\title{
O QUE SABEM ESTUDANTES DE MEDICINA SOBRE DOAÇÃO E TRANSPLANTES DE ÓRGÃOS NO BRASIL?
}

\section{What do medical students know about organ donation and transplantation in Brazil?}

\author{
Ana Rúbia Dacencio de Rosso; Nicole Carbone; Elie Kamilos Di Ciurcio; João Victor Sardinha Fantin; \\ Guilherme de Menezes Succi
}

\section{RESUMO}

Objetivo: Avaliar o conhecimento de estudantes de uma faculdade de Medicina sobre doação de órgãos e a organização do sistema de transplantes no Brasil. Método: Foram aplicados questionários de forma virtual a estudantes de Medicina, após aceite do Termo de Consentimento Livre e Esclarecido. Os dados foram resumidos pela frequência relativa e frequência absoluta para as variáveis qualitativas e como média \pm desvio padrão, mediana e percentis para as variáveis quantitativas. Resultados: Participaram da pesquisa 327 alunos do primeiro ao sexto ano de Medicina. Dentre eles, $62,4 \%$ do primeiro ou segundo ano, 20,2\% do terceiro ano, 9,5\% do quarto e 8,0\% do internato. Quase 90\% (87,2\%) afirmaram conhecer a possibilidade de doação de órgãos de doador falecido e também entre vivos (desde que respeitadas as normas legais vigentes). Apenas $70,6 \%$ afirmaram conhecer que a fila de transplante é única e nacional. Quase $30 \%$ dos participantes desconhecem a existência de financiamento pelo Sistema Único de Saúde e 8,9\% afirmaram que os planos de saúde devem dar cobertura a todo tipo de transplante. Menos da metade dos alunos participantes (41,6\%) disse não ser doador. O índice de acerto foi maior entre alunos do internato quando comparados aos demais para a maioria das perguntas. Conclusões: Ainda há por parte dos estudantes de Medicina avaliados desconhecimento sobre questões relativas à organização do sistema e outros assuntos relacionados a transplantes de órgãos no Brasil. O conhecimento dos alunos sobre o tema aumenta conforme progridem no curso, sendo maior entre aqueles do internato. São necessárias discussões sobre o tema em atividades curriculares e também em ações de extensão.

Descritores: Doador de Órgão; Transplante; Doação de Órgãos; Estudantes de Medicina.

\section{Instituição:}

Curso de Medicina da Faculdade São Leopoldo Mandic, Campinas/ SP, Brasil

\section{Correspondência:}

Guilherme de Menezes Succi

Rua José Rocha Junqueira, 13 - Swift, CEP 13045-755, Campinas/SP +55 19 3211-3722.

guilherme.succi@sImandic.edu.br

Recebido em: 06/10/2020
Aceito em: $13 / 11 / 2020$

\section{INTRODUÇÃO}

Transplante de órgãos tem sido um dos maiores desafios da humanidade nos últimos anos, graças a várias condições que levam à essa necessidade; entre elas podemos citar o alto número de patologias que levam à necessidade de transplante, o grande número de pessoas esperando por um órgão e o baixo índice de doadores. No Brasil, o primeiro transplante de órgão de doador falecido foi um transplante renal ocorrido em 1964, no Rio de Janeiro. Após essa data e com o advento das melhorias das técnicas cirúrgicas, desenvolvimento de drogas imunossupressoras (como a ciclosporina em 1938), ${ }^{1}$ aprimoramento dos cuidados intensivos pós-cirúrgicos e o uso de soluções de preservação dos órgãos mais eficientes, observamos um aumento exponencial da realização de transplantes. 
Com esse aumento do número de transplantes, era preciso uma lei que regulamentasse essa atividade no país. Foi então que houve a criação da Lei 9.434 de $1997,{ }^{2}$ que regulamentou o processo de doação e retirada de órgãos, que tinha como diretrizes a "gratuidade da doação, a beneficência em relação aos receptores e a não maleficência em relação aos doadores vivos".

Após anos, essa lei foi modificada pela Lei Federal 10.211, de 23 de março de $2001,{ }^{3}$ que criou o Registro Nacional de Doadores e definiu prioridade no Instituto Médico Legal (IML) para necropsias de doadores vítimas de morte violenta, visando a rápida liberação do corpo para a família. A normativa atual permite a doação de órgãos intervivos entre parentes de até quarto grau. Fora disso, a doação intervivos é permitida somente com autorização judicial, excetuando-se os casos de transplante de medula óssea. Na mesma lei está expresso que a autorização para a retirada de órgãos de doador falecido pode ser emitida somente por cônjuge ou parente até $2^{\circ}$ grau inclusive, desde que maior de idade, firmada em documento com duas testemunhas.

A limitação restrita para doação intervivos, além das normativas que obrigam a existência de grau de parentesco nas cirurgias de transplante de rim, pulmão e fígado, tornam essa modalidade nem sempre viável. O número de doadores efetivos tem enfrentado grandes dificuldades de crescimento no Brasil, tendo ficado abaixo dos 18 pmp (pacientes por milhão de população) em 2018, segundo relatório anual do Registro Brasileiro de Transplantes. ${ }^{4}$ Mesmo com crescimento significativo nesta década, passando de 10,7pmp em 2011 para os $17 \mathrm{pmp}$ atuais, ainda há evidente escassez de doadores. Outro fator de extrema relevância no baixo índice de doadores falecidos pode ser demonstrada através de um estudo desenvolvido por Moraes e Massarollo (1995), que apontou serem os principais motivos de recusa da doação de órgãos: a crença religiosa, a espera de um milagre, a não compreensão do diagnóstico de morte encefálica (ME) e a crença na reversão do quadro, a não aceitação da manipulação do corpo, o medo da reação da família, a inadequação na informação e a ausência de confirmação da ME, a desconfiança na assistência e medo do comércio de órgãos, a inadequação no processo de doação, o desejo do paciente falecido manifestado em vida de não ser doador de órgãos e o medo da perda do ente querido. ${ }^{5}$

Após a identificação do paciente com possível diagnóstico de ME, a notificação à Central de Notificação, Captação e Distribuição de Órgãos (CNCDO) da respectiva Unidade da Federação é de caráter compulsório. Os familiares devem ser então informados sobre a suspeita diagnóstica e da abertura do protocolo de determinação de ME. É somente após a confirmação do diagnóstico de ME que o médico assistente abordará a família sobre a possibilidade de doação de órgãos. Apesar das recorrentes campanhas governamentais sobre a importância da doação de órgãos, a falta de conhecimento da população geral sobre o tema e a difícil situação emocional que envolve o momento do diagnóstico de ME no ente querido mantêm o índice de recusa familiar à doação acima de $40 \%$ em $2018 .{ }^{4}$

A estruturação do Sistema Nacional de Transplantes (SNT) criado em 1997 foi regulamentada pela Portaria 2600 , de $2009 .{ }^{6}$ Nela são definidos os itens de estrutura e funcionamento do SNT.

A coordenação logística e a distribuição de órgãos e tecidos para transplantes são de responsabilidade da Central de Notificação, Captação e Distribuição de Órgãos (CNCDO), e realizadas em âmbito nacional pela Central Nacional de Transplantes (CNT), e em âmbito estadual pelas Secretarias de Saúde dos Estados/ Secretaria Estadual de Transplantes. As Organizações de Procura de Órgãos (OPO) fazem parte desse processo de coordenação, e sua criação depende das CNCDO, que atuam de maneira regionalizada, em parceria com as Comissões Intra-Hospitalares de Doação de Órgãos e Tecidos para Transplante (CIHDOTT), proporcionando educação continuada na área da doação de órgãos; auxílio aos hospitais para a identificação dos potenciais doadores e auxílio no processo de diagnóstico de ME, bem como na conclusão do processo de doação e transplante.

As CIHDOTT são comissões que atuam com o propósito de melhorar a identificação e manutenção de potenciais doadores. Elas também têm caráter educativo e articulam-se com as OPO. São obrigatórias em todos os hospitais públicos e privados do país com mais de 80 leitos. $^{6}$

Em um país continental como o Brasil, com grande diversidade de serviços hospitalares e superlotação nos hospitais, há ainda a dificuldade em se manter clinicamente estáveis os doadores falecidos, de maneira a se efetivar o transplante. Em artigo sobre as razões de descarte de doadores por equipes de transplante cardíaco no Brasil, Feldman e colaboradores descrevem como as principais razões para o descarte: idade avançada do doador, história médica insuficiente, ocorrência de parada cardíaca, uso de drogas vasoativas e instabilidade hemodinâmica. ${ }^{6}$ Esses dados mostram que ainda há muito o que se avançar na conscientização de profissionais da saúde e do público leigo sobre a importância do transplante e da doação de órgãos, bem como sobre o cuidado no suporte ao possível doador falecido. Esta pesquisa tem o objetivo de avaliar o conhecimento de estudantes de Medicina sobre a doação de órgãos e a organização do sistema de transplantes no Brasil. 


\section{MÉTODOS}

O estudo foi do tipo exploratório, descritivo e transversal sobre a opinião/conhecimento dos alunos de Medicina, do primeiro ao último ano da Faculdade São Leopoldo Mandic, situada no bairro Swift, na cidade de Campinas/ SP, a partir de abril de 2019 a julho de 2019, com relação à doação/transplante de órgãos e tecidos no Brasil.

Através da plataforma Google Forms, de maneira digital e após a assinatura de Termo de Consentimento Livre e Esclarecido (TCLE), os participantes responderam a um questionário autoaplicável com perguntas fechadas que abrangiam aspectos da doação de órgãos e da organização do sistema de transplantes de órgãos no Brasil.

Os dados das entrevistas foram resumidos pela frequência relativa e frequência absoluta para as variáveis qualitativas e como média \pm desvio padrão, mediana e percentis para as variáveis quantitativas.

$\mathrm{Na}$ estatística de inferência para variáveis qualitativas foi utilizado o teste Qui-Quadrado ou teste Exato de Fisher, quando alguma das frequências esperadas fosse menor ou igual a cinco; já no caso das variáveis quantitativas foi utilizado o Teste T de Student ou o Teste de MannWhitney, caso a amostra não apresentasse distribuição normal. Adotou-se nível de significância de 5\% (alpha = 0,05).

\section{RESULTADOS}

Participaram da pesquisa 327 alunos do primeiro ao sexto ano de Medicina da Faculdade São Leopoldo Mandic. Dentre eles, $62,4 \%$ do primeiro ou segundo ano, $20,2 \%$ do terceiro ano, $9,5 \%$ do quarto e $8,0 \%$ do internato (Figura 1). Quase a totalidade $(96,02 \%)$ dos alunos declararam que a doação de órgãos não é obrigatória no Brasil. Apenas $37,0 \%$ dos alunos conhecem as condições legalmente aceitas para doação de órgãos entre pessoas vivas: esta é permitida entre cônjuges ou parentes até quarto grau. Para $45 \%$ dos alunos, a doação intervivos é possível apenas com autorização judicial, o que não representa a realidade vigente no Brasil.

Quanto à questão sobre o que é preciso fazer para tornar-se doador de órgãos, $58,7 \%$ assinalaram a resposta correta, afirmando ser preciso comunicar à família ou ao responsável legal, pois são eles que fornecem a autorização necessária para que a doação se efetive. Entretanto, 23,9\% alegaram que é preciso deixar uma declaração registrando ser ou não doador, e $15,6 \%$ relataram que é preciso registrar em RG ou Carteira Nacional de Habilitação se a pessoa é ou não doadora. Para 1,8\% não há necessidade de qualquer ação do indivíduo interessado em tornar-se doador, pois o transplante no Brasil é obrigatório. Houve relação positiva entre estar mais avançado no curso e saber a resposta correta $(p=0,0127)$.

Figura 1 - Relação de alunos participantes segundo ano de matrícula no curso de Medicina

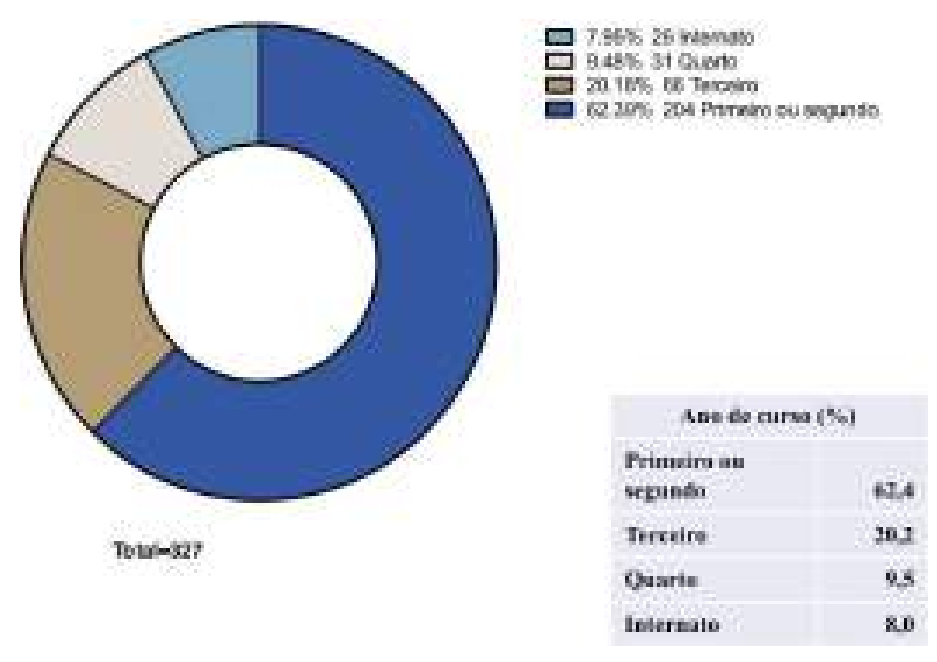

Sobre a definição de $\mathrm{ME}, 61,2 \%$ responderam corretamente, definindo-a como situação de ausência de fluxo sanguíneo cerebral, em que há irreversível perda de suas funções. No entanto, $35,8 \%$ dos participantes afirmaram erroneamente tratar-se de situação de coma profundo, sem resposta a estímulos.

Quase 90\% (87,2\%) afirmaram conhecer a possibilidade de doação de órgãos de doador falecido e também entre vivos (desde que respeitadas as normas legais vigentes). Sobre quais órgãos podem ser doados, os participantes apontaram como possíveis, a partir de lista oferecida: coração $(97,6 \%)$, rim $(97,6 \%)$, córneas $(95,1 \%)$, medula óssea $(93,9 \%)$, fígado $(93,9 \%)$, pulmão $(82,3 \%)$, pele $(82,6 \%)$, pâncreas $(64,5 \%)$, valvas cardíacas $(48,6 \%)$, ossos (44\%), intestino (42,8\%). A doação de nervos, apesar de não realizada, foi considerada possível para $20,7 \%$ dos entrevistados.

Para $66,4 \%$ dos participantes, a doação Inter vivos entre pessoas desconhecidas é proibida, demonstrando desconhecimento da possibilidade de doação com autorização judicial. Além disso, 26,6\% afirmaram erroneamente não ser permitida a doação entre cônjuges. Quando perguntados sobre quais órgãos podem ser doados entre pessoas vivas, $94,5 \%$ disseram ser possível a doação de rim, $67 \%$ de fígado e $90,5 \%$ da medula óssea. Surpreendentemente, $12,8 \%$ responderam ser possível a doação de córnea entre vivos. 
Apenas $70,6 \%$ afirmaram conhecer que a fila de transplante é única e nacional. Quase $30 \%$ dos participantes desconhecema existência definanciamento pelo SUS e $8,9 \%$ afirmaram que os planos de saúde devem dar cobertura a todo tipo de transplante.

Menos da metade dos alunos participantes $(41,6 \%)$ disseram não ser doadores. Entre aqueles que se apresentaram como doadores, $80,63 \%$ informaram à sua família a decisão, em comparação com $20,59 \%$ entre os não doadores. (Teste Exato de Fisher $p<0,000001$ ).

Pouco mais da metade dos participantes (52,6\%) responderam corretamente à pergunta sobre o fornecimento de atestado de óbito por causas naturais. Este é fornecido pelo hospital em que o doador esteve internado e traz como hora da morte o horário de confirmação de ME. Para 32,1\% ele é fornecido apenas por médico legista, não sendo possível determinar o horário exato do óbito antes da retirada completa desses órgãos, já que haverá procedimento cirúrgico para a retirada de órgãos para transplante. $O$ índice de acerto foi maior entre os alunos do internato, quando comparados aos demais (Teste de Qui Quadrado; $p=$ 0,0135).

Pouco mais da metade $(56,3 \%)$ acertou a pergunta sobre quem pode realizar a determinação de ME do doador de órgãos, que pode ser realizada por dois médicos habilitados, neurologistas ou não, que farão suas avaliações independentes, com intervalo mínimo de uma hora, devendo ser confirmada por pelo menos um exame complementar. A escolha da resposta correta foi mais frequente entre os alunos do internato (Teste do Qui Quadrado $p=0,013551$ ). Para $12,8 \%$, a determinação da ME somente pode ser confirmada após autorização da família, o que não corresponde à verdade.

Menos da metade (47,7\%) dos participantes demonstraram reconhecer a obrigatoriedade de constituição de Comissões Intra-Hospitalares de Doação de Órgãos e Tecidos para Transplantes (CIHDOTT), que são obrigatórias para todos os hospitais públicos ou privados com mais de 80 leitos. Para $27,2 \%$, as CIHDOTT são obrigatórias somente para Hospitais que realizam ou pretendam realizar cirurgias de transplante de órgãos.

A Faculdade São Leopoldo Mandic possui uma recémcriada Liga Acadêmica de Transplantes de Órgãos e tecidos e apenas $6,4 \%$ dos indivíduos da pesquisa declararam participar dela.

Quando perguntados sobre o critério de distribuição dos órgãos doados aos pacientes listados, $86,2 \%$ afirmaram corretamente que este obedece a aspectos segundo a gravidade do paciente - primazia dos órgãos aos pacientes mais graves (Figura 2). Apenas $30 \%$ dos participantes mostraram desconhecer que a maioria dos procedimentos é de financiamento exclusivo pelo
Sistema Único de Saúde (Figura 3). Para $88,7 \%$ dos participantes, o tema transplante de órgãos e tecidos deve ser abordado durante as atividades curriculares do curso de graduação em Medicina.

Figura 2 - Resposta dos participantes à pergunta: Segundo o Sistema Nacional de Transplantes, podemos afirmar sobre a fila de transplantes no Brasil

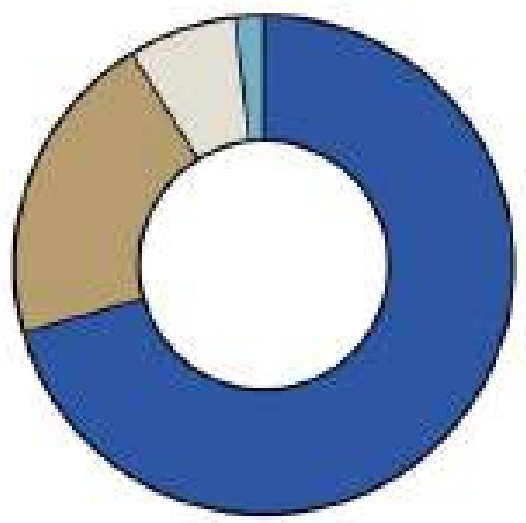

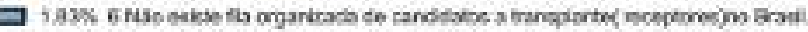

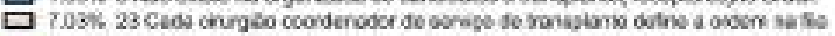

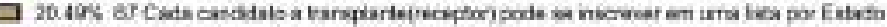

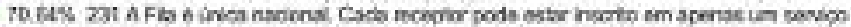

Figura 3 - Resposta dos participantes sobre seu conhecimento a respeito da fonte pagadora de transplantes de órgãos no Brasil.

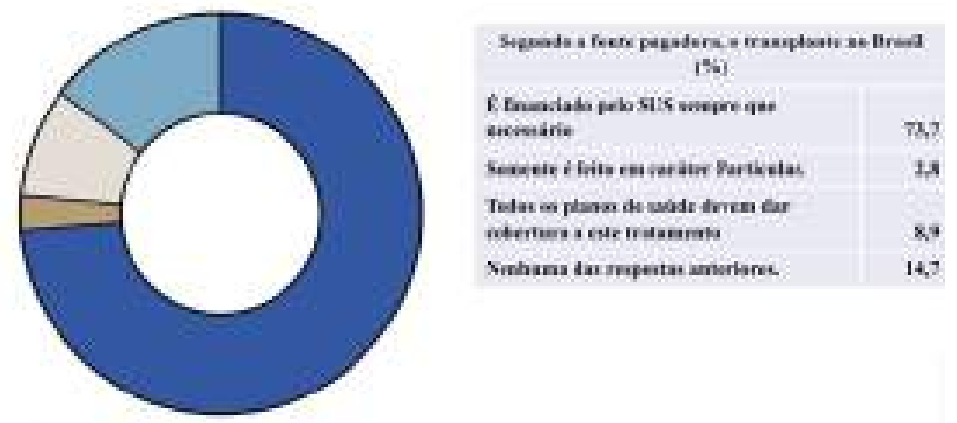

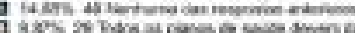

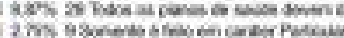

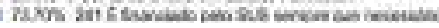

\section{DISCUSSÃO}

Os alunos participantes correspondiam a cerca de $30 \%$ dos matriculados no curso de Medicina de nossa Instituição no momento da realização da pesquisa. Entretanto, houve maior participação entre aqueles cursando os primeiros dois anos do curso, reduzindo gradativamente até os anos de internato. Este fato deve-se provavelmente à menor presença dos alunos de internato em sala de aula, já que estes se encontram, 
predominantemente, nas unidades de saúde em ambientes externos e participam menos de atividades de ligas em nossa faculdade.

Atualmente, segundo dados do Ministério da Saúde, houve um aumento expressivo de transplante de órgãos e tecidos no Brasil entre 2001 e 2018, de 107,64\%.7 Entretanto, apesar dos números serem promissores, ainda há longa fila de espera por um órgão. De acordo com a Associação Brasileira de Transplantes de Órgãos, havia 36.468 pacientes ativos na lista de espera de transplante de órgãos no Brasil em setembro de 2019. No ano de 2012 este número era de 26.662 pacientes. ${ }^{8,9}$

Os altos índices de recusa familiar para doação contribuem indiscutivelmente para que a fila permaneça crescendo. ${ }^{9}$ A recusa por sua vez, deriva de diversos motivos, tais como impedimento por questões religiosas, pouco tempo disponível aos familiares para a tomada de decisão sobre a doação, desconhecimento da vontade do possível doador sobre a doação e até despreparo do profissional que realiza a entrevista com os familiares. ${ }^{9}$ Certamente, fatores emocionais e ligados à situação de luto contribuem para a redução do aceite da doação.

Em pesquisa de Coelho e Bonella ${ }^{10}$ há uma comparação dos sistemas de transplante do Brasil e da Espanha. Os dois países destacam-se: o Brasil por ter o maior sistema público de transplantes de órgãos do mundo e a Espanha por manter há décadas, o maior índice de doadores efetivos por milhão de pessoas. Enquanto no país Europeu o índice de doadores por milhão foi de 46,7 em 2017, alcançando índice de 16,6 no Brasil no mesmo ano. Além disso, o índice de aceitação de doação pelas famílias chega a $87 \%$ na Espanha, que conta com um sistema nacional de transplantes (Organización Nacional de Trasplantes), criado em 1989. O sucesso espanhol deve-se certamente a diversos fatores, tais como: grande empenho na realização de campanhas de educação popular sobre o tema, capacitações continuadas de profissionais de saúde e também um canal telefônico disponível, em tempo integral, para que a população possa tirar suas dúvidas com um especialista no tema.

Esse contexto e a importância do tema são motivos da criação da Liga Acadêmica de Transplantes de Órgãos e Tecidos da Faculdade São Leopoldo Mandic. É importante a difusão de informações sobre a realidade do transplante de órgãos, tanto para acadêmicos de Medicina quanto para a população leiga. Para que esse assunto não seja abordado apenas em congressos da área da saúde, atingindo profissionais já sensibilizados, deve-se estimular também a discussão na sociedade.

Em nossa pesquisa, identificamos que a maioria dos alunos $(86,2 \%)$ considera como razão primordial de alocação na fila a gravidade do paciente receptor.
Dado semelhante foi obtido na pesquisa de Galvão e colaboradores, ${ }^{11}$ onde esse critério foi apontado por $66,6 \%$ dos entrevistados. A lista de espera de transplantes no Brasil é organizada por um sistema de "fila única nacional", ou seja, a cada surgimento de um novo doador a Central é informada, processando a seleção de possíveis receptores para os órgãos. Desta forma, além da gravidade clínica do receptor, analisam-se também tipo sanguíneo, peso e altura do doador e perfil de histocompatibilidade. Todas essas características, a cada oferta de órgão, influenciam na alocação do mesmo e no posicionamento do receptor na fila.

Ainda no estudo de Galvão e colaboradores, ${ }^{11}$ 94,3\% dos participantes consideraram que os procedimentos de transplantes deveriam ter seus custos cobertos por planos de saúde. Em nossa pesquisa, 30\% dos participantes mostraram desconhecer que a maioria dos procedimentos é de financiamento exclusivo pelo Sistema Único de Saúde. Por outro lado, nas duas pesquisas houve evidente aumento do conhecimento sobre diagnóstico de ME quando da participação de alunos de anos mais avançados do curso de Medicina, mostrando a responsabilidade da graduação na formação do profissional de saúde.

Em relação ao conhecimento sobre a definição de morte encefálica (ME), Janine Schirmer e colaboradores 12 observaram que a maioria dos estudantes de ensino médio $(73,9 \%)$ apontaram corretamente a ME como a ausência de fluxo sanguíneo com perda das funções cerebrais. Em nossa pesquisa, a resposta correta foi apontada por $61,2 \%$.

Nosso estudo tem limitações por ter sido realizado de maneira unicêntrica e envolver apenas alunos de Instituição Particular de Ensino Superior. Além disso, a participação menor de alunos do internato pode ser considerada como viés negativo para o acerto das respostas.

Apesar dos avanços obtidos nos últimos anos, ainda há necessidade de maior dedicação na formação de profissionais de saúde e na educação da população leiga em assuntos relacionados ao transplante de órgãos. Casos de sucesso, como o verificado na Espanha, devem servir de exemplo para o Brasil.

\section{CONCLUSÕES}

Ainda há, por parte dos estudantes de Medicina avaliados, desconhecimento sobre questões relativas à organização do sistema e outros assuntos relacionados a transplantes de órgãos no Brasil.

O conhecimento dos alunos sobre o tema aumenta conforme progridem no curso, sendo maior entre aqueles do internato. São necessárias discussões sobre o tema em atividades curriculares e também em ações de extensão como a Liga de Transplantes. 


\section{ABSTRACT}

Purpose: To assess the knowledge of medical students from a single medical school on organ donation and the organization of the transplant system in Brazil. Methods: Questionnaires were virtually applied to medical students after their acceptance of the Free and Informed Consent Form. Data were summarized by the relative and absolute frequency for qualitative variables and as mean \pm standard deviation, median and percentiles for quantitative variables. Results: 327 students from the first to the sixth year of Medicine participated in the research. Among them, $62.4 \%$ from the first or second year, $20.2 \%$ from the third year, $9.5 \%$ from the fourth and $8.0 \%$ from the last two years. Almost $90 \%(87.2 \%)$ said they were aware on the possibility of donating organs from a deceased donor, and also among the living (provided that the current legal rules are respected). Only $70.6 \%$ said they were aware that the transplant queue is unique and national. Almost $30 \%$ of participants are unaware of the existence of funding by the Public Health System, and $8.9 \%$ stated that health plans should cover all types of transplants. Less than half of the participating students (41.6\%) said they were not donors. The success rate was higher among students in the last two years of medical school when compared to others for most questions. Conclusions: There is still, on the part of the assessed medical students, ignorance about issues related to the organization of the system and other issues related to organ transplants in Brazil. The knowledge of the students on the topic increases as they progress in the course, being higher among those in the two final years of medical school. Discussions on the topic are necessary in curricular activities and also in extension programs.

Keywords: Organ Donors; Transplantation; Organ Donation; Students, Medical.

\section{AGRADECIMENTOS}

Aos alunos participantes do núcleo da Liga de Transplantes pela colaboração na missão de difusão do conhecimento sobre transplantes de órgãos. À professora Juliana Almada Colucci pela análise estatística e auxílio na interpretação dos dados da pesquisa.

\section{REFERÊNCIAS}

1. Starzl T, Hakala T, Rosenthal J, Iwatsuki S, Shaw Jr B. The Colorado-Pittsburgh cadaveric renal transplantation study with cyclosporine. In: Transplantation proceedings. NIH Public Access; 1983 Dec;15(4 Suppl 1):2459-62

2. Brasil, República $P$ da. Lei no 10.211 , de 23 de março de 2001. Altera dispositivos da Lei no 9.434 , de 4 de fevereiro de 1997, que "dispõe sobre a remoção de órgãos, tecidos e partes do corpo humano para fins de transplante e tratamento". Diário Oficial da União. 2001;

3. Brasil, Brasil. Lei n. 9.434 de 4 de fevereiro de 1997. Dispõe sobre a remoção de órgãos, tecidos e partes do corpo humano para fins de transplante e tratamento e dá outras providências. Diário Oficial da República Federativa do Brasil. 1997;(Seção 1).

4. Associação Brasileira de Transplante de Órgãos. Dimensionamento dos transplantes no Brasil e em cada estado (2011-2018). RBT Registro Brasileiro de Transplantes. 2018;24(4):1-101. Disponível em: http://www.abto.org.br/ abtov03/Upload/file/RBT/2018/Lv_RBT-2018.pdf.

5. Moraes EL, Massarollo MCKB. Recusa de doação de órgãos e tecidos para transplante relatados por familiares de potenciais doadores. Acta paulista de enfermagem. 2009;22(2):131-5.

6. Feldman A, Marcelino CAG, Prado LB, Fusco CC, de Araújo MN, Ayoub AC, et al. Reasons for refusing a donor heart for transplantation in Brazil. Clinical transplantation. 2016:30(7):774-8.
7. Ministério da Saúde. Portal de Arquivos. [homepage na internet]. Número de Transplantes no Brasil de 2001 a 2018. [acesso em 25 Set 2020]. Disponível em: https:// portalarquivos2.saude.gov.br/images/pdf/2019/julho/03/ BRASIL.pdf.

8. Associação Brasileira de Transplante de Órgãos. Dados numéricos da doação de órgãos e transplantes realizados por estado e instituição no período: janeiro / setembro - 2019. RBT Registro Brasileiro de Transplantes. 2019;25(3):1-23. Disponível em: http:// www.abto.org.br/abtov03/Upload/file/RBT/2018/Lv_RBT2018.pdf.

9. Pessoa JLE, Schirmer J, Roza BA. Avaliação das causas de recusa familiar a doação de órgãos e tecidos. Acta Paulista de Enfermagem. 2013;26(4):323-30.

10. Coelho GHF, Bonella AE. Doação de órgãos e tecidos humanos: a transplantação na Espanha e no Brasil. Revista Bioética. 2019;27(3):419-29.

11. Galvão FH, Caires RA, Azevedo-Neto RS, Mory EK, Figueira ER, Otsuzi TS, et al. Conhecimento e opinião de estudantes de Medicina sobre doação e transplante de órgãos. Rev Assoc Med Bras. 2007;53(5):401-6.

12. Schirmer J, Leite RF, Roza BA, Silva AS, Fujinami $\mathrm{TI}$, Lemos $\mathrm{M}$, et al. Doação de órgãos e tecidos: o que sabem os estudantes do ensino médio. Einstein. 2007;5(3):213-9. 